\title{
Sufragio femenino y representación por Leonor Causa
}

\author{
Female suffrage and Representation by Leonor Causa
}

\author{
Paula Alonso \\ The George Washington University, EE. UU. \\ http://orcid.org/0000-0002-2491-0581 \\ palonso@gwu.edu
}

El artículo adjunto fue publicado al mes siguiente de concluirse los debates en el Senado Nacional acerca del proyecto de ley sobre sufragio femenino presentado por el peronismo, el cual, luego de ser aprobado, pasó a la Cámara de Diputados. Dicho debate tuvo escasa repercusión en la prensa y evidenció la heterogeneidad de voces sobre el tema dentro de la coalición triunfante en las elecciones presidenciales de febrero de ese año. Una vez que pasó a la Cámara de Diputados, el proyecto se "peronizó" y "evitizó", es decir, se homogeneizó la postura ambigua del peronismo sobre el tema de los derechos de la mujer y su lugar en la sociedad. Evita se puso al frente de la campaña que establecería una línea inequívoca y directa entre el derecho al voto de la mujer y Perón. Por lo tanto, el artículo aparecido en la revista Mundo Argentino en septiembre de 1946, una revista dedicada a mujeres de clase media y alta, precedió dichas transformaciones.

El artículo refleja el enfrentamiento ya existente entre las sufragistas y Perón. Desde su lugar en el gobierno de facto, Perón había anunciado en 1945 su intención de avanzar con un decreto que otorgue el voto a la mujer, una medida que no era resistida ya por ningún grupo político. El 
anuncio tuvo el efecto de abroquelar a las diversas agrupaciones sufragistas, uniéndolas en su oposición a Perón bajo el argumento de que dicha medida no debería provenir de un gobierno militar sino de uno elegido democráticamente. Mientras Perón abandonó momentáneamente su plan, no fue de extrańar que incluyera en su primer discurso de apertura del Congreso su intención de convertir el proyecto en ley. La intención de este artículo, por lo tanto, es subrayar la larga historia de la lucha por el sufragio femenino en la Argentina, haciendo hincapié en sus principales hitos y en algunas de sus principales figuras. El artículo no hace alusión a las divisiones y fracturas que caracterizaron dicha historia y no hace referencia alguna a Perón o al partido que introdujo el proyecto en el recinto del Senado, intentando desactivar una vinculación que la oposición denunciaba como estratégica del peronismo, con el fin captar el agradecido voto femenino.

Más relevante, sin embargo, es el segundo aspecto de este artículo, el que se pregunta sobre lo que hará la mujer en caso de ser elegida. A diferencia del voto, sobre lo cual no había oposición, ya que cada partido competía por acreditarse su bandera, las escasas menciones en el Senado y en la prensa sobre la posibilidad de que la mujer pueda ser representante fue una idea cuestionada por peronistas y antiperonistas. La propuesta de Mundo Argentino, al dedicarle un amplio espacio a presentar una visión positiva sobre la posibilidad de mujeres en el gobierno, representa una excepción. El artículo se destaca por presentar las voces de mujeres pertenecientes a distintas agrupaciones políticas, excluyendo a peronistas. Las diferentes posturas contaban con tradiciones ya conocidas, en las que las líderes comunistas colocaban el foco de atención en la clase obrera y las radicales en cuestiones partidarias y de libertades políticas. A diferencia del común cuestionamiento sobre la falta de educación cívica de la mujer para gobernar, la publicación destaca su capacidad y preparación, además de incluir el antecedente histórico de cuando, en 1928, una mujer se postuló como candidata a la presidencia.

Las mujeres argentinas votaron por primera vez en elecciones nacionales en 1951, en las que participó el 90\% del padrón, sobrepasando el voto masculino. La representación femenina, sin embargo, tardaría en madurar, un déficit que la Ley de cupos de 1991, la primera en el mundo en obligar a los partidos políticos a incluir una proporción de mujeres en sus listas, se propuso remediar. El artículo, por lo tanto, no solo fue original en su contenido sino también precoz en sus aspiraciones. 


\title{
Que harán las mujeres si llegan a gobernar ${ }^{1}$
}

\author{
Leonor Causa
}

BUENOS AIRES, 11 DE SEPTIEMBRE DE 1946

El Senado de la Nación acaba de aprobar el proyecto de ley por el cual se acuerdan a la mujer los mismos derechos políticos que en nuestro régimen electoral se le reconocen al hombre. Se cumple, con esto, una vieja aspiración de miles de mujeres argentinas, y se da fin a un período de luchas que abarcan no menos de siete lustros y que comprenden los nombres de las mentalidades femeninas más significativas de la patria en lo que va de este siglo.

El movimiento feminista se inició aquí, en efecto, como una repercusión lógica de lo que Europa había logrado en este sentido, pero no sin que antes, pasando por alto las dificultades nacidas de la incomprensión, de la influencia de las tradiciones, que se traducían en la burla y el desprecio, y la hostilidad con que se recibían en el ambiente las manifestaciones de esta naturaleza, muchas mujeres se arriesgaran a frecuentar las aulas de la enseñanza media y superior. Y fue en septiembre de 1906 cuando, a raíz de la celebración en Buenos Aires del Primer Congreso Internacional del Libre Pensamiento, se constituyó el primer "Centro Feminista" que se habilitó entre nosotros. Esta iniciativa, que rompió el hielo, tuvo en la práctica muy corta vida, no obstante lo cual hemos de reconocerle el mérito de haber dado lugar a que se congregasen mujeres de las más diversas opiniones políticas en una sola aspiración: la de trabajar juntas en favor de su emancipación civil y política.

En 1910 -del 18 al 23 de mayo- fue celebrado en esta capital el Primer Congreso Femenino Internacional, convocado por la "Asociación Universitaria Argentina”. Inspiró a sus organizadoras el propósito

Artículo publicado en la revista Mundo Argentino (Registro Nacional de la Propiedad Intelectual No. 135.191), en Buenos Aires, el 11 de septiembre de 1946. Agradezco a Sophia Kics, de la Universidad de Notre Dame, por su colaboración transcribiendo este texto. 
de asociarse al primer centenario de la revolución argentina, en la que cupo a la mujer tan destacada actuación. Y en las actas de este congreso se hacían muchas proposiciones, que son hoy realidad, en especial las que se refieren a los derechos civiles de la mujer. En las deliberaciones de aquellos días participaron figuras femeninas que representaban a lo mejor de la época, no sólo por su entereza moral sino por la voluntad puesta a prueba en su empeño. Entre ellas hallábase Cecilia Grierson, la primera médica argentina, presidenta del congreso; la doctora Julieta Lanteri, su secretaria y mujer a quien le cupo una descollante y larga actuación como agitadora y fundadora del "Partido Feminista"; la doctora Sara Justo, tesorera; la doctora Atilia Canetti de Rosales, Alicia B. de Guillot, Raquel Camaña, la doctora Isabel Kaminsky y Carolina Muzzlil, obrera esta última con grandes condiciones, realizó una labor estimable en favor de la legislación del trabajo de las mujeres y los niños. La doctora Grierson, comisionada en 1899 por el Consejo Internacional de Mujeres en Londres para fundar la rama argentina, lo hizo en 1900, ocupando en él el cargo de vicepresidenta honoraria, lo que dio lugar a que el Consejo Nacional la separara de su cargo como profesora, comunicando el hecho con una circular que decía, entre otras cosas: "La doctora Grierson ha presidido un Congreso Feminista Liberal”.

Así, con estos sacrificios, quedó abierto el camino que después siguieron Elvira Rawson de Dellepiane, Emilia Salza, Alfonsina Storni, Alicia Moreau de Justo, Emma Day, Adelia di Carlo, Lucila de Gregorio Lavie y otras que sería largo enumerar.

\section{UNA CANDIDATA A LA PRESIDENCIA DE LA REPÚBLICA}

A partir de 1906 hubo siempre grupos alentados por mujeres de señalado prestigio que tenían, entre sus propósitos, la obtención del sufragio femenino. Así, por ejemplo, "Universitarias Argentinas", cuya alma fue la doctora Sara Justo; el Partido Feminista de la doctora Lanteri, la Sociedad Juana Manuela Gorriti y la Liga Pro Derechos de la Mujer, que animó la doctora Elvira Rawson de Dellepiane, fundadora, con Alicia Moreau de Justo, en 1918. Esta última institución organizó, en 1920, con motivo de las elecciones generales y municipales que se celebraban en la fecha, simulacros de voto femenino, siguiendo la táctica empleada por las feministas parisienses el año anterior. 
Pero quizá mucho más eficaz como prueba que esta manifestación sufragista fue la candidatura a la Presidencia de la República que el Partido Comunista Obrero otorgó, por primera y única vez en el país, a una de sus líderes: Angélica Mendoza.

Cuando, el otro día, en el recinto de la Cámara se preguntó, por un diputado, si la equiparación de derechos permitía que una mujer pudiese desempeñar la primera magistratura y se lo contestó que sí, quizá nadie recordaba entre los miembros del Congreso este hecho singular.

Angélica Mendoza, hoy profesora de castellano en el Colegio Sarah Lawrence de Bronxville, Estados Unidos, mujer joven aún y de inteligencia reconocida en los medios intelectuales y políticos, fue, en efecto, candidata a la presidencia en las elecciones de 1928. En aquella oportunidad esta mujer, que paseó durante años por los barrios fabriles o frecuentando los centros partidarios su robustez doctrinaria, su familiaridad con los problemas sociales, sus condiciones de agitadora, supo salir al encuentro de los que hacían mofa de este gesto de sus correligionarios diciendo en voz alta: "Mi candidatura no es la demostración de galantería de mis compañeros que mucha gente supone. Es obra de otras razones mucho más serias para nuestro movimiento, sin descontar por ello lo remoto de su realización. El Partido Comunista Obrero ha proclamado mi nombre no por mero espíritu de feminismo, que está bien lejos de nuestra acción y de nuestros propósitos, sino como medio de propaganda y afirmación proletaria, dado mis conocimientos de los problemas del interior del país y mi vinculación con los conocimientos de los problemas del interior del país y mi vinculación con los trabajadores del interior y de la capital y, finalmente -a que no decirlo-, por mi condición de mujer que no puede excluir la capacidad para gobernar una nación”.

\section{Palabras de algunas posibles mujeres de gobierno}

Algunos partidos políticos del país cuentan, entre sus dirigentes, con mujeres que defienden sus respectivas causas, y constituyen dentro de sus filas elementos de agitación y de combate, El Partido Socialista, desde luego, figura con nombres como los de Alicia Moreau de Justo, vivida y compañera de causa de su fundador, y María L Berrondo; el 
comunismo tiene mujeres de empresa, como la doctora Alicia de la Peńa; el Partido Demócrata Nacional a la doctora Argúas; el radicalismo a la señora Elena Lecol de Noel y Rosa Rodríguez de la Torre, presidenta y secretaria, respectivamente, del Comité Femenino del partido.

¿Qué harían estas mujeres, a las que se supone, no sin razón, futuras candidatas a las posiciones de gobierno, en caso de salir electas en algún próximo debate elector? Oigámoslas.

"Pobre sentido histórico demuestran aquellos que dicen para qué sirve el voto de las mujeres si ellas no han cambiado nada -afirma la doctora Justo-. No comprenden que el sólo hecho de votar significa para quienes no lo han hecho nunca un cambio irreversible, un paso hacia la liberación de la conciencia, la adquisición de una responsabilidad nueva. Si las primeras generaciones de mujeres no parecen sino capaces de limitar, las que sigan serán más audaces. Aun admitiendo que carezcan de originalidad para actuar bastaría que reforzaran lo modestamente bueno y sano que puede hacerse en política para que su aporte fuese útil”.

Por su parte, la doctora Alcira de la Peña, líder comunista, quien cree que el gobierno debe arbitrar las medidas necesarias para la inmediata confección de los padrones, de modo que las mujeres argentinas podamos votar en las próximas elecciones, sostiene:

"Hay tanto que hacer en beneficio de las mujeres de nuestro país, que, de ser elegidas, nuestra tarea sería grande y los proyectos múltiples. Los millares de trabajadores incorporadas a las diversas industrias no tienen legislación adecuada para protegerlas. Sin estar en el parlamento, pero haciendo uso del derecho de petición, presentamos a Diputados, además de un proyecto sobre sufragio femenino, otro sobre "igual salario a igual trabajo". Es esta una aspiración de todas las trabajadoras, injustamente inferiorizadas en el pago del jornal, aunque su rendimiento y su eficacia estén abonados por su preponderancia en ciertas industrias, como en la textil 75 por ciento, frigoríficos 50 por ciento, metalurgia 17,000 obreras en capital y alrededores. Lo mismo en la industria del vestido, gráficos, etc. También presentamos dos proyectos de reformas: uno a la ley 11.317, para que se incluya además de las salas cunas obligatorias en las fábricas, jardines de infantes para atender a los hijos de las obreras hasta la edad escolar, y otro a la ley 11.933, en lo fundamental, suprimiendo el aporte obrero, que quedaría a cargo del patrón y del Estado, ampliando el descanso de las futuras madres a 45 días antes y 45 días 
después del nacimiento de sus niños, y extendiendo los beneficios de la ley a las trabajadores a domicilio, las servidoras domésticas y las empleadas profesionales".

A otros proyectos interesantes hace referencia la doctora De la Peńa, que la brevedad de esta crónica nos impide recoger. Oigamos, ahora, a la líder radical señorita De la Torre:

"Después de la escandalosa época de fraudes, arbitrariedades e injusticias de toda índole, considero que las mujeres tomaremos con serias reflexiones esta responsabilidad, influyendo con nuestra intervención en la conciencia de los hombres; renovando métodos y costumbres; teniendo como meta en nuestra aspiración el respeto a las libertades individuales.

Siendo así, sólo quedará por analizar toda ley, toda medida de gobierno, rechazando violentamente y sin dilación aquellas que tiendan a trabar o a coartar el libre desarrollo de las instituciones, llevando al país hacía una política dirigida.

Nuestra Constitución Nacional reconoce esas libertades individuales en primer término y las libertades económicas, asegurando las condiciones políticas y jurídicas que impulsan nuestro desenvolvimiento material, base del engrandecimiento, y ajustando todos los resortes de la organización nacional.

No anulándonos como fuerza eficiente que somos, traeremos nuevos planes y colaboraremos en la construcción de ellos, conquistando así, para el futuro, una sociedad mejor.

Para esto nos proponemos realizar, dentro del radicalismo, una acción doctrinaria, de introducción a la política; no porque creamos que la mujer se encuentra en inferioridad de condiciones intelectuales, sino que le falta el adiestramiento práctico. Nos proponemos abrir una tribuna del pensamiento radical, dándole todo su contenido filosófico.

Hemos puesto manos a la obra en tan honrosa tarea, comenzando por la organización partidaria. Aspiramos a colaborar a la liberación de las materiales angustias del pueblo, por medio del aprovechamiento de las fuentes de riquezas naturales y por el ordenamiento de la economía nacional, para que podamos gozar un día de ese clima de libertad a que todo ser humano tiene derecho, para que la vida moral y espiritual del pueblo pueda desarrollarse armónicamente". 


\section{LEYENDAS DE LAS IMÁGENES}

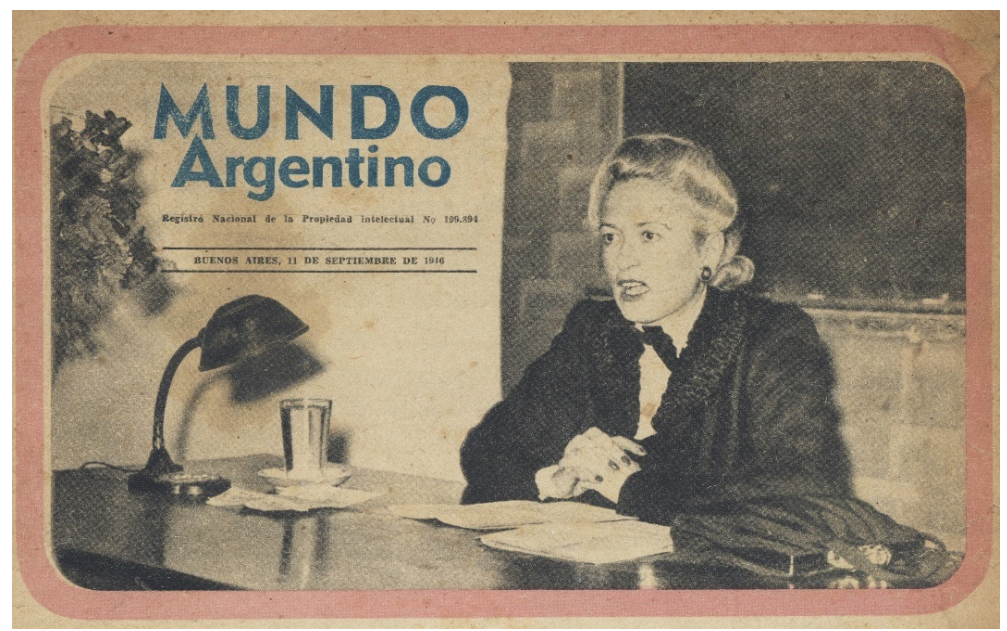

EL PARTIDO DEMÓCRATA NACIONAL tiene en la doctora Margarita Argúas a una de sus lideres más entusiastas y batalladoras en las luchas politicas.

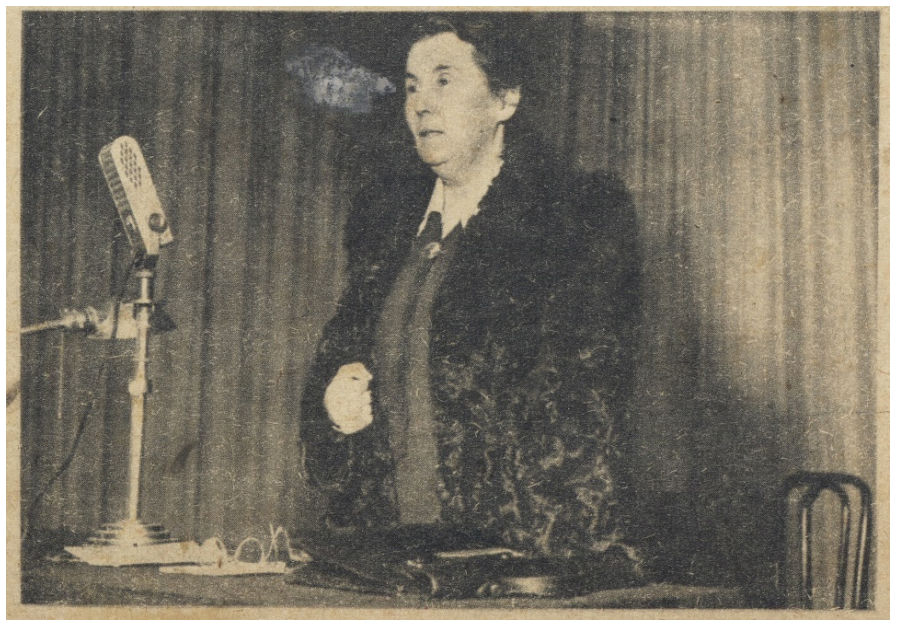

ALICIA MOREAU DE JUSTO, que fue la compañera del fundador del Partido Socialista argentino, en cuyas filas milita desde hace muchos años. 


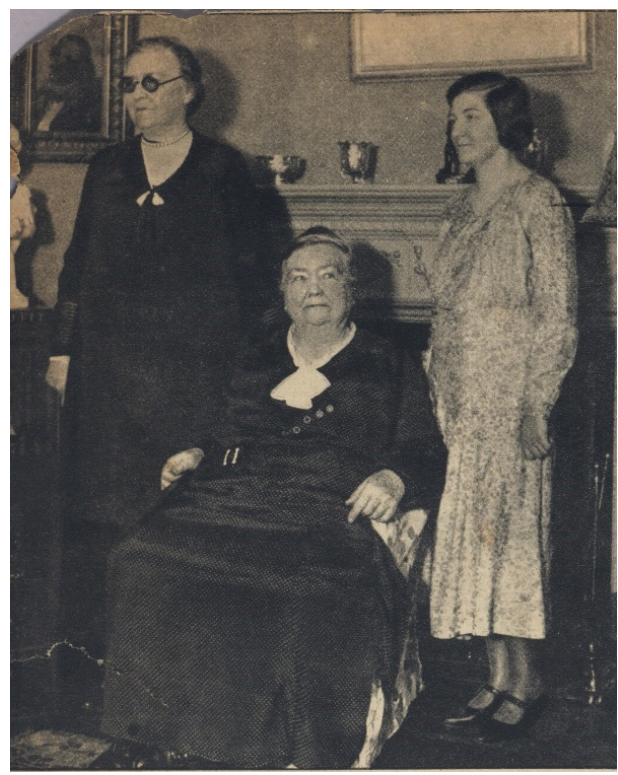

LA DOCTORA CECILIA GRIERSON, que abrió el camino de la liberación femenina y que en 1899 fue separada de su cargo por su acción feminista.

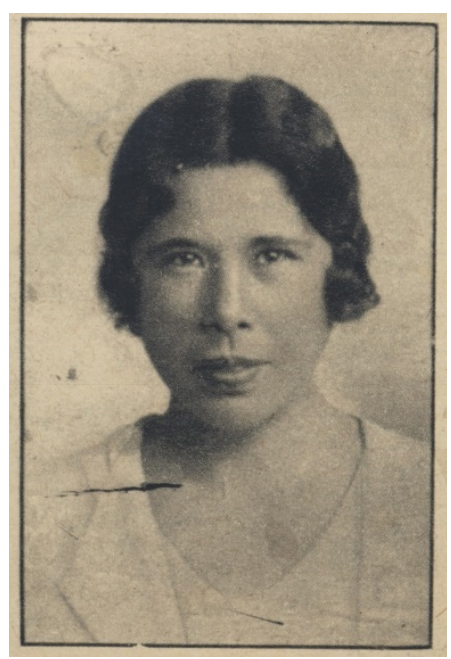

LA PRIMERA y única candidata a la presidencia que ha habido hasta hoy en nuestro país, Angélica Mendoza, en las elecciones de 1928. 


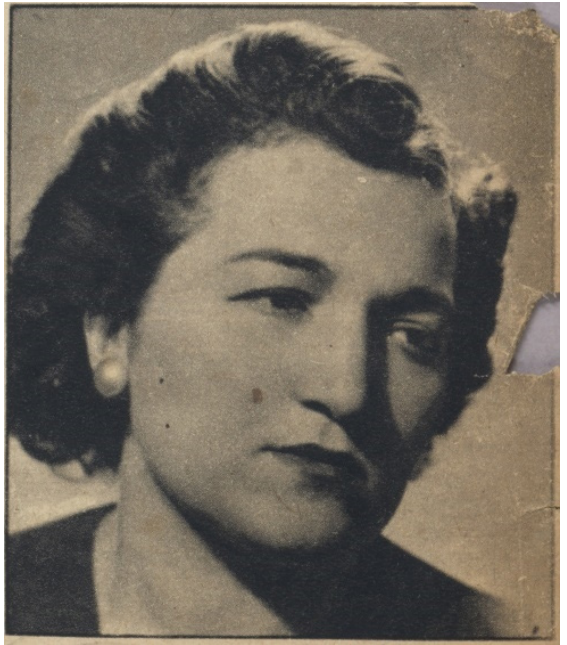

ROSA RODRÍGUEZ DE LA TORRE, líder radical, quien cree que la mujer gobernará colaborando por liberar al pueblo de sus angustias y problemas.

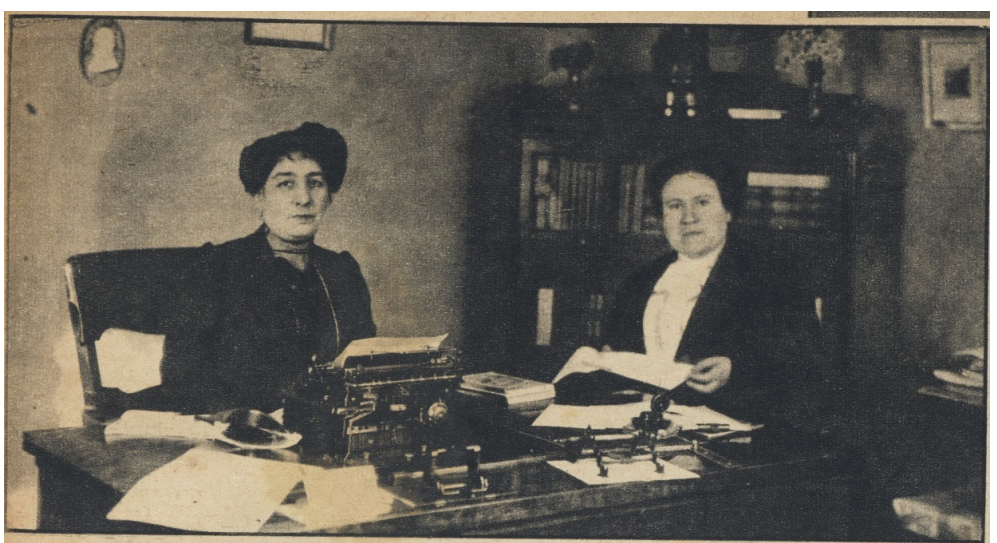

LA DOCTORA LANTERI RENSHAW (derecha), en una fotografía de 1929, dedicada a preparar una campaña electoral, con una colaboradora. 


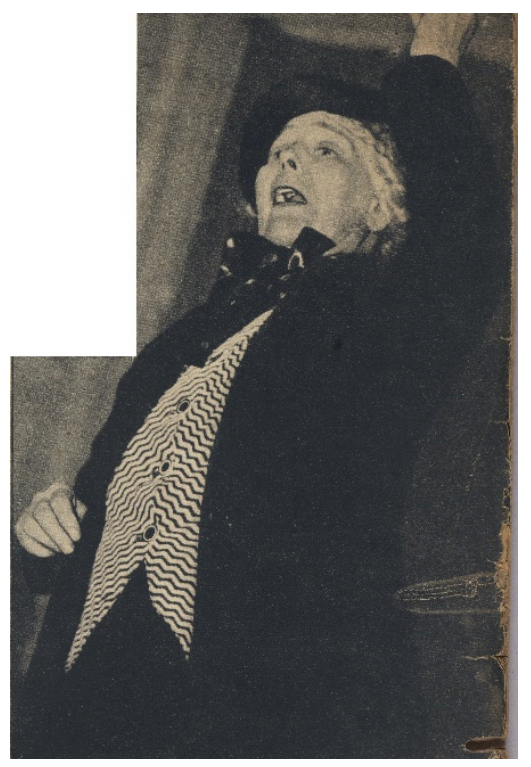

AL SER PRONUNCIADO, el nombre de la doctora Elvira Rawson de Dellepiane en la Cámara, se aplaudió en él a esta vieja luchadora liberal que, aun octogenaria, sigue dando un ejemplo de energía y capacidad para el trabajo.

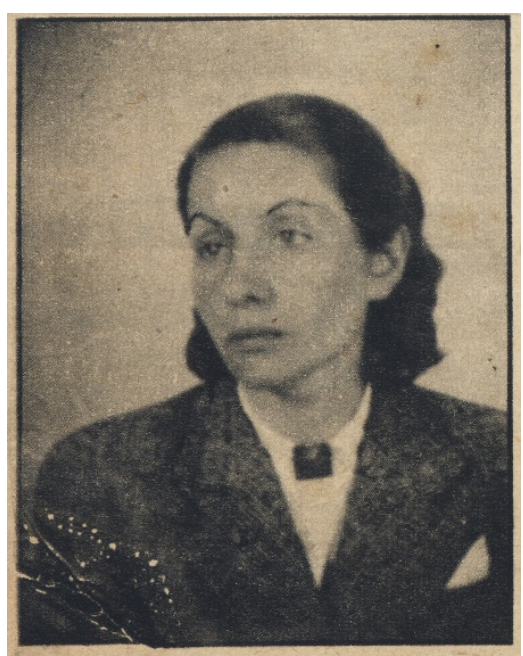

MILITANTE COMUNISTA, la doctora Alcira de la Peña sería un factor de lucha en el Congreso Nacional, si tuviera la suerte de llegar a él. 